\title{
Three Main Causes of Homocystinuria: CBS, cbIC and MTHFR Deficiency. What do they Have in Common?
}

\author{
Giovana Regina Weber Hoss ${ }^{1,2}$ (D), Soraia Poloni, ${ }^{1,2}$, Henk J Blom ${ }^{3}$, \\ Ida Vanessa Doederlein Schwartz ${ }^{1}$
}

\begin{abstract}
Genetic homocystinurias are a group of inborn errors of metabolism that result in the massive excretion of homocysteine (Hcy) in the urine due to Hcy accumulation in the body, usually causing neurological and cardiovascular complications. The three most frequent causes are classical homocystinuria [deficiency of cystathionine beta-synthase (CBS)], methylmalonic aciduria with homocystinuria, cblC type (cblC deficiency) and severe methylenetetrahydrofolate reductase (MTHFR) deficiency. In this review, we highlight the similarities and differences among these disorders. Briefly, their joint manifestation is the accumulation of tHcy, however, the other sulfur amino acids show various and even invers profiles. Vascular disease, developmental delay and seizures are found in all homocystinurias, nevertheless, the complications of CNS differ in a wide variety of presentations and severities and are apparently less pronounced in CBS deficiency. Moreover, patients with remethylation defects typically do not present ectopia lentis and bone disturbances, tall stature and osteoporosis. Whereas hematological alterations, such as megaloblastic anemia, thrombocytopenia neutropenia and life-threatening microangiopathy, are specific findings of cblC deficiency.
\end{abstract}

\section{Keywords}

classical homocystinuria, methylmalonic aciduria with homocystinuria, cblC type, Severe MTHFR deficiency.

\section{Background}

Hyperhomocysteinemia (tHcy $>15 \mu \mathrm{M})[1]$ can be caused by environmental (such as nutritional deficiency of vitamins B12 or folate) or genetic factors, including inborn errors of metabolism (Table 1). Mild or moderate forms of hyperhomocysteinemia are present in $5-10 \%$ of the population.[2] The severe form of hyperhomocysteinemia ( $\mathrm{tHcy}>50 \mu \mathrm{M})$ is rare, and typically associated with severe vitamin B12 or folate deficiency or inherited defects in Hcy metabolism. [3] Total Hcy (tHcy) consists of free Hcy (reduced plus oxidized Hcy in the non-protein fraction of plasma) and protein-bound Hcy.

Hcy is a sulfur-containing amino acid not used in protein synthesis and is considered toxic at increased levels. Hcy is formed as a product of methyl-transfer reactions in methionine (Met) metabolism. In this process, Met is activated by ATP into S-adenosylmethionine (SAM), which is the universal methyl group donor, resulting in the formation of S-adenosylhomocysteine (SAH). SAH is converted to Hcy and adenosine through S-adenosyl-L-homocysteine hydrolase
(SAHH). The equilibrium of the reaction favors the formation of SAH. As a consequence, increased Hcy should result in a pronounced accumulation of $\mathrm{SAH}$, which is a potent inhibitor of many methyltransferase reactions. While methylation is essential for cellular functions in all organs, Hcy is formed in all tissues, but its elimination via CBS (EC 4.2.1.23), in the transsulfuration pathway, is considered to only occur in the liver and kidney.

\footnotetext{
${ }^{1}$ Programa de Pós-Graduação em Genética e Biologia Molecular, Universidade Federal do Rio Grande do Sul, Porto Alegre, RS, Brazil

${ }^{2}$ Hospital de Clínicas de Porto Alegre, Porto Alegre, RS, Brazil

${ }^{3}$ Department of Internal Medicine, University Medical Centre Amsterdam, Amsterdam, Noord-Holland, Netherlands
}

Received July 8, 2019, and in revised form September 13, 2019. Accepted for publication October 28, 2019.

\section{Corresponding Author:}

Giovana Regina Weber Hoss, Programa de Pós-Graduação em Genética e Biologia Molecular, Universidade Federal do Rio Grande do Sul, Porto Alegre, RS, Brazil.

Email: giovana.weber@gmail.com 
Thus, in all other tissues, such as the vascular system and the brain, the only available possibilities to eliminate Hcy are remethylation by methionine synthase (MTR - EC 1.16.1.8) or exportation out of the cell.[4] In remethylation, Hcy receives a methyl group from 5-methyltetrahydrofolate (5MTHF), which is formed from 5,10-methylenetetrahydrofolate by MTHFR (methylenetetrahydrofolate reductase - EC 1.5.1.20) (Figure 1). Notably, 5MTHF is the circulating form of folate in blood and cerebrospinal fluid (CSF).

The active elimination of Hcy from the body is the main regulator of Met and methylation homeostasis and occurs in the liver and kidney via degradation by CBS. The liver and kidney also contain betaine-homocysteine methyltransferase (BHMT - EC 2.1.1.5), which is an alternative way of Hcy remethylation (Figure 1). SAM is the main regulator of Met, Hcy and so methylation status. In the liver excess of Met increases SAM, which activates CBS and inhibits MTHFR, causing Hcy to be primarily and irreversibly converted to cystathionine. [5,6] If Met is low then CBS is not activated and MTHFR is not inhibited by
SAM, causing Hcy to be mainly remethylated back to Met. [7,8] Vitamin B12, as methylcobalamin (Mecbl), is involved as a cofactor for MTR, which catalyzes the remethylation of Hcy into Met in the cytosol. Adenosylcobalamin (Adocbl) is the cofactor for methylmalonyl-CoA mutase, which converts methylmalonylCoA into succinyl-CoA in mitochondria (Figure 2).

This paper reviews the clinical and biochemical findings and management of the three most frequent genetic causes of homocystinurias: CBS deficiency or classical homocystinuria (HCU), methylmalonic aciduria with homocystinuria cblC type, and severe MTHFR deficiency. These three disorders all present with severe hyperhomocysteinemia, while Met levels are increased in HCU and decreased or normal in cblC and MTHFR deficiency, and methylmalonic acid (MMA) is increased only in cblC[9] (Table 1). Folate and Hcy metabolism are intertwined. As a consequence, defects in Hcy metabolism influence folate homeostasis. In CBS deficient patients at diagnosis folate is often deficient likely due to the inhibition of MTHFR resulting in decreases of 5MTHF, the circulation form of folate. In MTHFR

Table 1. Summary of genetic homocystinurias

\begin{tabular}{|c|c|c|c|}
\hline Disease (OMIM number) & Deficient Enzyme & Gene (Locus) & $\begin{array}{l}\text { Pattern of } \\
\text { Inheritance }\end{array}$ \\
\hline Classical homocystinuria (\# 236200) & Cystathionine beta-synthase (CBS - EC 4.2.1.23) & CBS (21q22.3) & $A R$ \\
\hline $\begin{array}{l}\text { Severe methylenetetrahydrofolate reductase } \\
\text { (MTHFR) deficiency (\# 236250) }\end{array}$ & Methylenetetrahydrofolate reductase (MTHFR - EC 1.5.1.20) & MTHFR (1p36.22) & $A R$ \\
\hline $\begin{array}{l}\text { Methylmalonic aciduria and homocystinuria, } \\
\text { cblC type (\# 277400) }\end{array}$ & $\begin{array}{l}\text { Methylmalonyl-CoA mutase (MUT - EC 5.4.99.2) } \\
\text { and methionine synthase (MTR - EC 1.16.1.8) }\end{array}$ & MMACHC (1p34.1) & $A R$ \\
\hline $\begin{array}{l}\text { Methylmalonic aciduria and homocystinuria, } \\
\text { cblC type, digenic (epi-cblC \#277400) }\end{array}$ & $\begin{array}{l}\text { Methylmalonyl-CoA mutase (MUT - EC 5.4.99.2) } \\
\text { and methionine synthase (MTR - EC 1.16.1.8) }\end{array}$ & $\begin{array}{l}\text { PRDX1 (1p34.1) } \\
\text { MAHCC (1p34.1) }\end{array}$ & AR \\
\hline $\begin{array}{l}\text { Methylmalonic aciduria and homocystinuria, } \\
\text { cbID type (\# 277410) }\end{array}$ & $\begin{array}{l}\text { Methylmalonyl-CoA mutase (MUT - EC 5.4.99.2) } \\
\text { and methionine synthase (MTR - EC 1.16.1.8) }\end{array}$ & MMADHC (2q23.2) & AR \\
\hline $\begin{array}{l}\text { Homocystinuria-megaloblastic anemia, cblE } \\
\text { type (\# 236270) }\end{array}$ & Methionine synthase reductase (MTRR - EC 2.1.1.135) & MTRR (5p15.31) & $A R$ \\
\hline $\begin{array}{l}\text { Methylmalonic aciduria and homocystinuria, } \\
\text { cblF type (\# 277380) }\end{array}$ & $\begin{array}{l}\text { Methylmalonyl-CoA mutase (MUT - EC 5.4.99.2) } \\
\text { and Methionine synthase (MTR - EC:2.1.1.13) }\end{array}$ & LMBRD1 $(6 q 13)$ & $A R$ \\
\hline $\begin{array}{l}\text { Homocystinuria-megaloblastic anemia, cblG } \\
\text { type (\# 250940) }\end{array}$ & Methionine synthase (MTR - EC:2.1.1.13) & $\operatorname{MTR}(1 q 43)$ & $A R$ \\
\hline $\begin{array}{l}\text { Methylmalonic aciduria and homocystinuria, } \\
\text { cbll type (\# 614857) }\end{array}$ & $\begin{array}{l}\text { Methylmalonyl-CoA mutase (MUT - EC 5.4.99.2) } \\
\text { and Methionine synthase (MTR - EC:2.1.1.13) }\end{array}$ & $A B C D 4(14 q 24.3)$ & $A R$ \\
\hline $\begin{array}{l}\text { Methylmalonic acidemia and homocystinuria, } \\
\text { cblX type (\# 309541) }\end{array}$ & $\begin{array}{l}\text { HCF-1; Transcriptional regulation of MMACHC. } \\
\text { Methylmalonyl-CoA mutase (MUT - EC 5.4.99.2) } \\
\text { and methionine synthase (MTR -EC 1.16.1.8) }\end{array}$ & HCFC1 (Xq28) & $X L R$ \\
\hline $\begin{array}{l}\text { Methylenetetrahydrofolate dehydrogenase } \\
\text { (MTHF) deficiency (\# 617780) }\end{array}$ & $\begin{array}{l}\text { 5,10-methylenetetrahydrofolate dehydrogenase (EC 1.5.1.5), } \\
\text { 5,10-methenyltetrahydrofolate cyclohydrolase (EC 3.5.4.9), } \\
\text { and 10-formyltetrahydrofolate synthetase (EC 6.3.4.3) }\end{array}$ & MTHFD1 (14q23.3) & $A R$ \\
\hline $\begin{array}{l}\text { Transcobalamin II (TC) deficiency } \\
(\# \text { 275350) }\end{array}$ & $\begin{array}{l}\text { Transcobalamin; Cellular delivery of cbl. Methylmalonyl-CoA } \\
\text { mutase (MUT - EC 5.4.99.2) } \\
\text { and methionine synthase (MTR -EC 1.16.1.8) }\end{array}$ & TCN2 (22q12.2) & $A R$ \\
\hline $\begin{array}{l}\text { Methylmalonic aciduria and homocystinuria, } \\
\text { TcblR type (\# 613646) }\end{array}$ & $\begin{array}{l}\text { TCbIR; Cellular receptor for TC. Methylmalonyl-CoA } \\
\text { mutase (MUT - EC 5.4.99.2) } \\
\text { and methionine synthase (MTR - EC 1.16.1.8) }\end{array}$ & CD320 (19p13.2) & $A R$ \\
\hline
\end{tabular}




\section{Methionine Cycle}

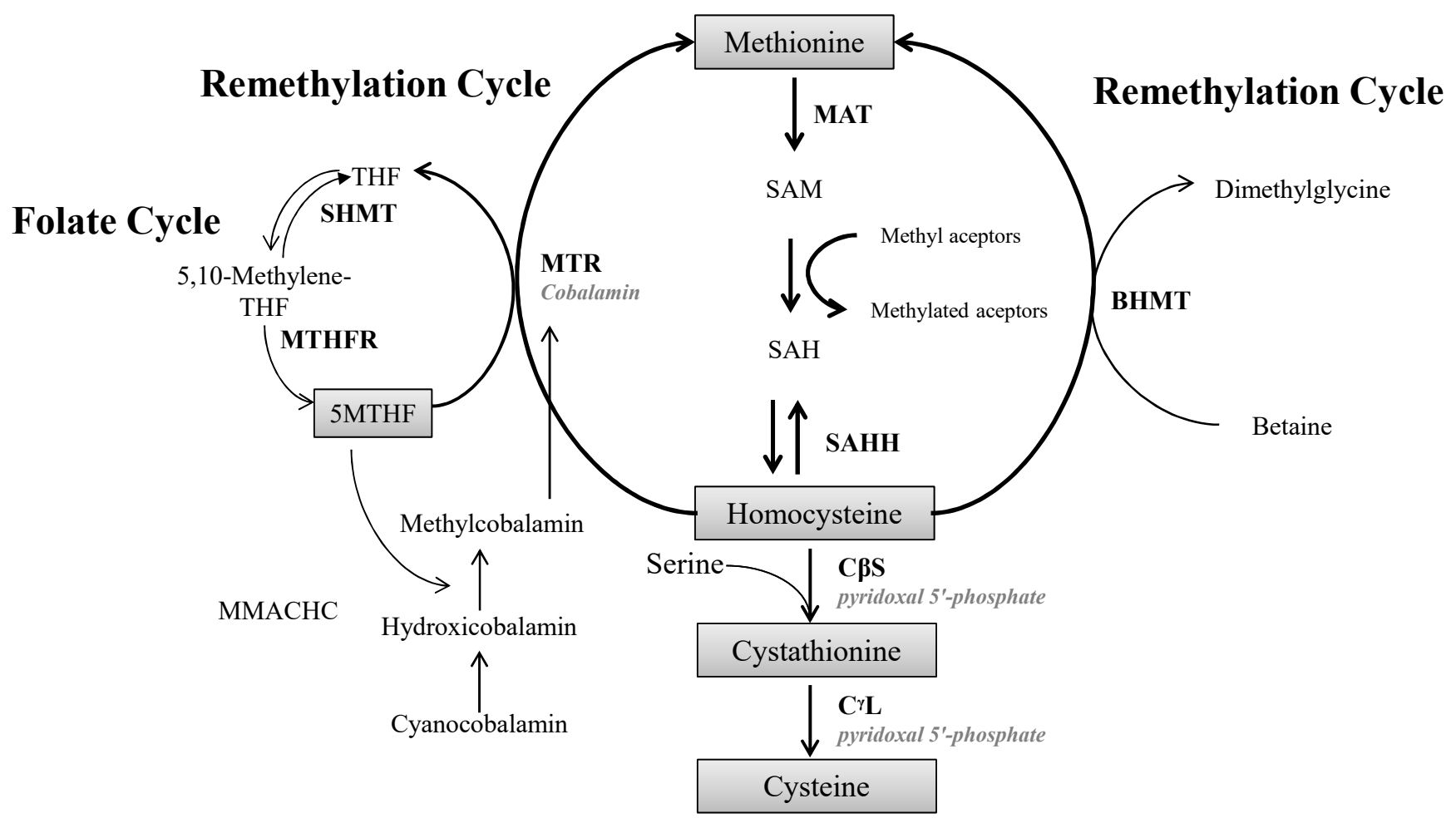

\section{Transsulfuration \\ Pathway}

Figure 1. Overview of homocysteine metabolism. MAT: methionine adenosyltransferase; SAM: S-adenosylmethionine; SAH: S-adenosylhomocysteine; SAHH: S-Adenosyl-homocysteine hydrolase; CBS: cystathionine $\beta$-synthase; C $\gamma$ L: cystathionine $\gamma$-lyase; MTR: methionine synthase; THF: tetrahydrofolate; MTHFR: 5,10-methylene-THF reductase; SHMT: serine-hydroxymethyltransferase; BHMT: betainehomocysteine methyltransferase; MMACHC: methylmalonic aciduria and homocystinuria type $\mathrm{C}$ protein; Enzymes are shown in capitals, and their cofactors in italics.

deficiency folate is severely deficient, whereas in cblC defect all folates accumulate as 5MTHF resulting in functional cellular folate deficiency.

\section{Classical Homocystinuria}

\section{Clinical presentation}

CBS deficiency or classical homocystinuria (HCU; OMIM $+236200)$ is the most common type of homocystinuria. The prevalence of HCU dramatically varies between regions from 1:240 at the Orchid Island to less than one in one million in the Taiwanese Han population.[10] The worldwide prevalence is estimated at 1:100,000 to 1:344,000 individuals.[11,12]

Four organ systems are primarily affected in HCU: ocular, vascular, central nervous (CNS) and skeletal[13] (Table 2). The hallmark study of Mudd et al. in 1985 concerns a cohort of over 600 patients. According to this survey, eye disease, particularly lens dislocation (ectopia lentis), was the main reason for $\mathrm{HCU}$ investigation (85\% of the cases) and commonly the first symptom, manifesting after the age of two years old and affecting more than $50 \%$ of non-treated patients at the age of 10 years old. [14] Other ocular abnormalities that might occur in HCU include high myopia, iridodonesis, glaucoma, optic atrophy, retinal degeneration, retinal detachment, cataracts and corneal abnormalities.[11,15-17]

Another common feature of $\mathrm{HCU}$ is vascular disease. Thromboembolic events can occur at any age and at any vein. $[14,18-21]$ Although it is less common than eye disease, $50 \%$ of non-treated patients presented a thromboembolic event at age 29 , and the importance of this disease is demonstrated by the high mortality rate from vascular complications. In Mudd's survey[14], over $70 \%$ of the deceased patients died because of thromboembolism. Special circumstances, such as pregnancy, surgery and association with mutations in Factor V, seem to increase the risk of vascular events. [22-24] Interestingly, recent studies showed that vascular manifestations can be the sole symptom and can appear even after the second or third decade 


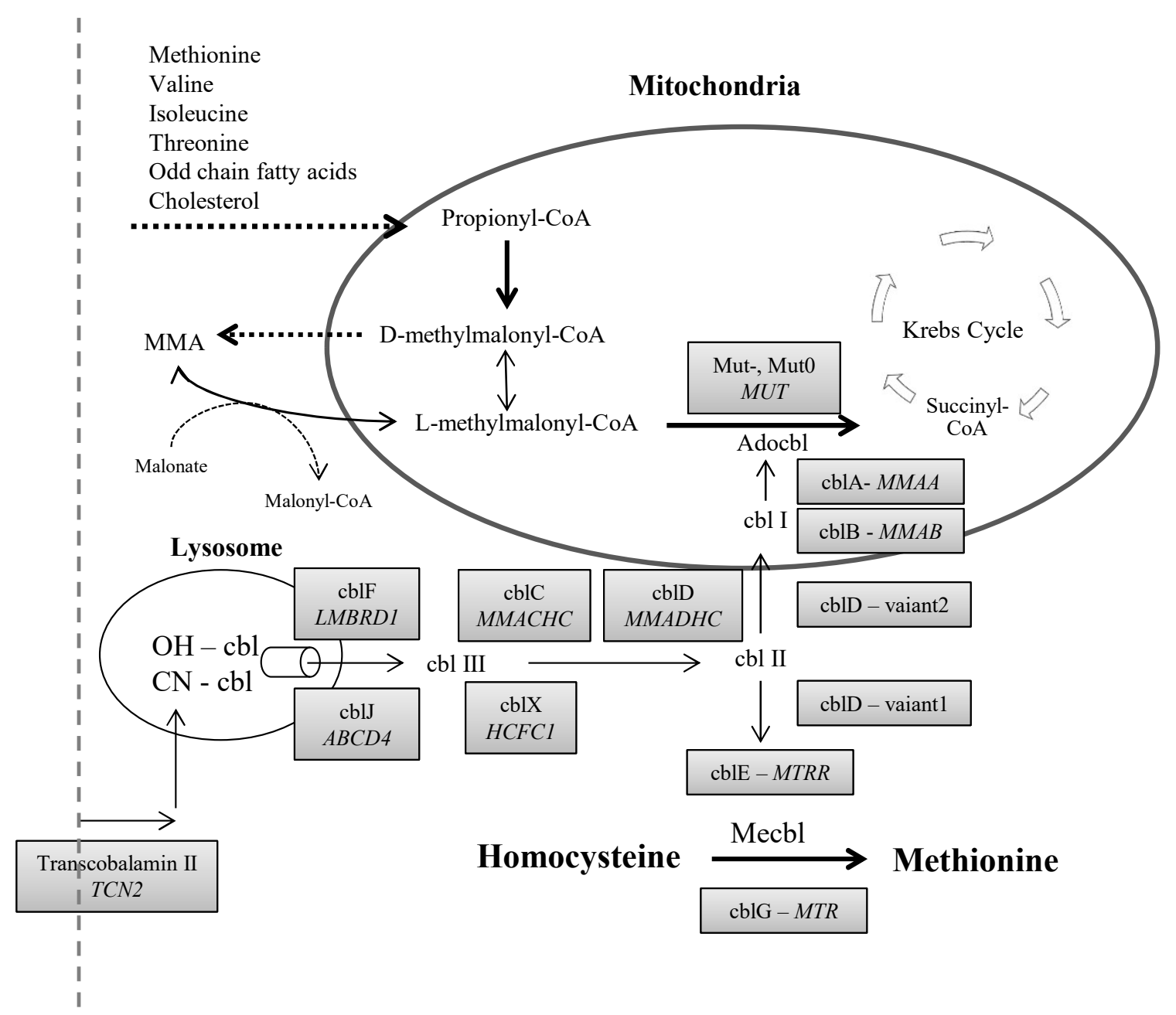

Figure 2. Overview of B12 metabolism. MMA: methylmalonic acid; MUT: methylmalonyl CoA mutase; Mut -: partial loss of MUT function; Mut 0: complete loss of MUT function; Adocbl: adenosylcobalamin; cbl: cobalamin; MMAA: Methylmalonic aciduria type A; MMAB: Methylmalonic Aciduria cbIB Type; MMADHC: methylmalonic aciduria and homocystinuria type D; MMACHC: methylmalonic aciduria and homocystinuria type $\mathrm{C}$ protein; LMBRD1: gene that encodes a lysosomal membrane protein that may be involved in the transport and metabolism of cobalamin affected in cblF; ABCD4: gene ATP binding cassette subfamily D member 4 related to cblj; HCFC1: gene host cell factor $\mathrm{C} 1$ related to cblX; OH-cbl: hydroxocobalamin; $\mathrm{CN}$-cbl: cyanocobalamin; TCN2: transcobalamin 2; MTRR: gene methionine synthase reductase related to cblE; Mecbl: Methylcobalamin and MTR: methionine synthase related to cblG.

of life, especially in patients homozygous for the CBS c.833 T>C (p.Ile278Thr) mutation.[18, 25]

Cognitive impairment is also considered a common CNS manifestation of HCU. In Mudd's survey, a wide range of IQ's from 10 to 138 was reported, with a median of 78.[14] A recent study from Qatar observed that patients early diagnosed by neonatal screening had significantly higher intelligence quotient, quality of life, and adherence to treatment when compared with the late diagnosed patients.[26] In addition to the direct toxicity of Hcy on CNS, recurrent strokes can also impact cognitive skills.[11,22] Seizures occur in nearly $20 \%$ of the patients.[14] Psychiatric disorders are also highly prevalent, affecting up to $50 \%$ of patients.[27] Schizophrenia, anxiety and depression are well documented in HCU.[11,27-30] The most common symptoms observed by Abbott et al., (1987) in 63 patients include episodic depression (10\%), chronic behavior disorders (17\%), chronic obsessive-compulsive disorder (5\%), and personality disorders (19\%).[27] Additionally, psychiatric disorder as an isolated symptom of $\mathrm{HCU}$ has been reported.[31, 32]

The skeletal features of HCU include osteoporosis and osteopenia, scoliosis, dolichostenomelia, tall stature, genu valgum, sternal deformities and arachnodactyly.[14,33] The most frequent finding is osteoporosis, which affects approximately half of nontreated patients in their second decade of life.[14] In addition to eye abnormalities (ectopia lentis), the bone deformities (with the exception of osteoporosis) resemble those observed in Marfan Syndrome, what has led to misdiagnosis in the past.[34] Other clinical findings reported in HCU include hypopigmentation of the hair and skin and malar flush, and there is a case report on acute pancreatitis and chronic diarrhea.[35-38] 
Table 2. Biochemical presentation and clinical manifestation of non-treated homocystinuria disorders due to CBS, cblC and MTHFR defects

\begin{tabular}{|c|c|c|c|}
\hline & CBS & cblc & MTHFR \\
\hline Homocysteine & $\uparrow \uparrow$ & $\uparrow \uparrow$ & $\uparrow \uparrow$ \\
\hline Methionine & $\uparrow \uparrow *$ & Normal or $\downarrow$ & Normal or $\downarrow$ \\
\hline Cystathionine & $\downarrow \downarrow *$ & $\uparrow \uparrow$ & $\uparrow \uparrow$ \\
\hline Methylmalonic acid & Normal & $\uparrow \uparrow * *$ & Normal \\
\hline Cysteine & $\downarrow \downarrow$ & $\downarrow$ & $\downarrow$ \\
\hline \multicolumn{4}{|l|}{ Clinical findings in common } \\
\hline Central nervous system & $\begin{array}{l}\text { Seizures, psychiatric disorders, } \\
\text { mental retardation. }\end{array}$ & $\begin{array}{c}\text { Early onset: seizures, } \\
\text { mental retardation } \\
\text { Late onset: psychiatric disorder, } \\
\text { mental retardation. }\end{array}$ & $\begin{array}{l}\text { Early onset: seizures, } \\
\text { mental retardation } \\
\text { Late onset: psychiatric } \\
\text { disorder, mental retardation. }\end{array}$ \\
\hline $\begin{array}{l}\text { Cardiovascular, Vessels } \\
\text { and hematology }\end{array}$ & Thromboembolism & Thromboembolism & Thromboembolism \\
\hline \multicolumn{4}{|l|}{ More specific clinical findings } \\
\hline Central nervous system & $\begin{array}{l}\text { Sequelae of thromboembolic } \\
\text { events* }\end{array}$ & $\begin{array}{c}\text { Early onset: Microcephaly, } \\
\text { hydrocephalus, cortical atrophy**, } \\
\text { hypotonia, lethargy, developmental delay. } \\
\text { Late onset: Acute neurologic } \\
\text { decompensation, extrapyramidal } \\
\text { symptoms and tremor. }\end{array}$ & $\begin{array}{c}\text { Early onset: Hypotonia, lethargy, apnea***, } \\
\text { paresthesias***, feeding problems*** and } \\
\text { eventually microcephaly. } \\
\text { Late onset: progressive encephalopathy, } \\
\text { ataxia, spasticity. }\end{array}$ \\
\hline Eye & $\begin{array}{l}\text { Ectopia lentis*, myopia* } \\
\text { and glaucoma* }\end{array}$ & $\begin{array}{c}\text { Pigmentary retinopathy**, } \\
\text { nystagmus** and decreased visual acuity. }\end{array}$ & - \\
\hline Bone & $\begin{array}{l}\text { Normal to tall stature and } \\
\text { generalized osteoporosis* }\end{array}$ & - & - \\
\hline $\begin{array}{l}\text { Cardiovascular, Vessels and } \\
\text { hematology }\end{array}$ & - & $\begin{array}{c}\text { Megaloblastic anemia**, thrombocytopenia** } \\
\text { and neutropenia** }\end{array}$ & - \\
\hline \multicolumn{4}{|l|}{ Treatment } \\
\hline & $\begin{array}{l}\text { Pyridoxine, folinic acid, dietary } \\
\text { Met restriction, betaine, } \\
\text { acetylsalicylic acid for patients } \\
\text { with high thrombosis risk. }\end{array}$ & $\begin{array}{l}\text { High dose of OHcbl, betaine, } \\
\text { Met supplementation }\end{array}$ & $\begin{array}{l}\text { Betaine, OHcbl, folinic acid, } \\
\text { Met supplementation, riboflavin } \\
\text { and pyridoxine. }\end{array}$ \\
\hline
\end{tabular}

*Specific of CBS deficiency; *** Specific of cbIC deficiency; **** Specific of MTHFR deficiency. Met: methionine; OHcbl: hydroxycobalamin.

\section{Diagnosis}

Markedly high tHcy $(>50 \mu \mathrm{mol} / \mathrm{L}$ in children; tHcy $>100 \mu \mathrm{mol} / \mathrm{L}$ in adults) together with increased Met and low cysteine in plasma are the classical biochemical features of HCU (Table 2). However, these biochemical abnormalities may be less pronounced in patients with milder forms of HCU or those taking vitamin supplements[22, 38, 39].

Confirmation can be made via the measurement of CBS activity (typically in fibroblasts). Since this method is not broadly available, molecular genetic analysis is most often used for confirmation of the diagnosis. DNA analysis can also be performed, especially in high-risk populations, for newborn screening and families with known CBS mutations. The human $C B S$ gene is located at chromosome 21q22.3[40], and more than 200 disease-causing mutations have been identified [41]. \{Stenson, 2017, The Human Gene Mutation Database: towards a comprehensive repository of inherited mutation data for medical research', genetic diagnosis and next-generation sequencing studies\}\{Stenson, 2017, The Human Gene Mutation Database: towards a comprehensive repository of inherited mutation data for medical research', genetic diagnosis and next-generation sequencing studies\} The most frequent mutations (p.Ile278Thr, p.Thr191Met and p.Gly307Ser) account for nearly half of the HCU alleles worldwide (http://cbs.lf1.cuni.cz/index.php). Prenatal diagnosis can be achieved by molecular genetic analyses or the extraction and culture of cells from amniotic fluid to measure CBS activity.[11, 42, 43]

Newborn screening has been performed, especially in countries with high incidences of HCU, such as Ireland and Qatar.[44, 45] The most common method is the measurement of Met in dried blood spots, but a high proportion of false negatives have been obtained by using this method.[46-48] The accuracy of Met to detect HCU is low since, in particular, the pyridoxineresponsive forms of HCU do not develop hypermethioninemia 
in the first days of life. In addition, other diseases can also lead to increased Met concentrations.[49] To increase sensitivity, reducing the cutoff for Met has been suggested.[49] In high-risk populations, the direct measurement of tHcy in DBS or analyses of $C B S$ mutations should be performed.[50-52]

\section{Management}

CBS deficiency results in markedly increased plasma levels of tHcy and Met and low cysteine.[11,22] The main goal in HCU treatment is to reduce tHcy $(<50 \mu \mathrm{mol} / \mathrm{L}$ for pyridoxine responsive and $<100 \mu \mathrm{mol} / \mathrm{L}$ for non-responsive patients[13]). The first strategy in the treatment is to test whether the patient is pyridoxine responsive. Pyridoxal phosphate, the active form of pyridoxine, is a co-factor of CBS and high dose of pyridoxine administrations markedly decreases tHcy in approximately $50 \%$ of HCU patients. $[14,53]$ Dosages from 100 to $500 \mathrm{mg} /$ day in adults can be used. $[9,38]$ Typically, patients who are responsive to pyridoxine present delayed and less severe clinical symptoms and these individuals may not even require any additional treatment.[13,14] In addition to pyridoxine, oral folinic acid supplementation (1 to 5 $\mathrm{mg} /$ day) should be administered because many patients are folate deficient at the time of diagnosis. Pyridoxine responsiveness should only be tested under normal folate levels. $[9,39,54,55]$

If pyridoxine plus folate is not able to reduce tHcy levels to the target values, then additional therapies should be used. A very efficient strategy to lower tHcy is dietary Met restriction. Met is an essential amino acid and a diet low in Met will result in a significant decline of tHcy. To meet protein and micronutrient requirements, a free-Met amino acid-based formula should be taken daily. The amount of Met tolerated per patient varies from 15 to $60 \mathrm{mg} / \mathrm{kg} /$ day.[56] Poor compliance to diet is common, especially in adults and late diagnosed patients.

Betaine acts in the remethylation route through a pathway independent of folate.[5] Oral betaine supplementation (6 - 9 $\mathrm{g} /$ day or $150-250 \mathrm{mg} / \mathrm{kg} / \mathrm{day}$ ) can reduce tHcy more than $70 \%$, but this treatment results in an even more pronounced increase in Met. High levels of Met are acceptable, as long as this molecule does not exceed $1000 \mu \mathrm{mol} / \mathrm{L}$, as levels higher may cause cerebral edema. [39,52,54]

Cobalamin (cbl) or vitamin B12 participates in the remethylation route together with folate, and its deficiency is common in HCU; thus, vitamin B12 should be monitored and supplemented when deficient.[9,39] $\mathrm{N}$-acetylcysteine may be administered to increase cysteine levels.[13] For patients with high thrombosis risk (previous thromboembolic event or mutations in factor V), salicylic acid is recommended.[39]

Good metabolic control from the neonatal period and thereafter is capable to prevent the clinical manifestations of HCU.[14, 26, 57, 58] In late diagnosed patients, treatment can also significantly prevents morbidity and mortality.[44] Even when tHcy remained higher than the target values, a major reduction in vascular disease risk is observed in HCU patients.[20]

\section{Methylmalonic Aciduria and Homocystinuria, Cblc Type}

\section{Clinical Picture}

Methylmalonic aciduria and homocystinuria cblC type (MIM\# 277400 ) is rare but remains the most common inborn error of cbl metabolism.[59] Newborn screening studies suggest that the incidence of cblC deficiency was higher than the previous estimate of 1/200,000 births.[60] A neonatal screening program in New York state estimates the incidence of cblC as approximately 1:100,000 live births.[61] and according to Han et al. (2015), the incidence of cblC was approximately $1: 3,920$ in Shandong Province, China.[62]

In 1969, the first case was reported by Mudd et al., concerning an infant with homocystinuria, methylmalonic aciduria, cystathioninemia, and hypomethioninemia. The infant died at 7.5 weeks of age. In vitro analysis identified a defect in the two reactions in which vitamin B12 derivatives function as coenzymes: 1) Met formation from 5MTHF and Hcy by MTR, and 2) the isomerization of methylmalonyl-CoA to succinylCoA (MUT) (Figure 2). Since vitamin B12 was present at normal concentrations in the liver, these authors concluded that the gene-determined defect involved the conversion of B12 to the active coenzymes.[63]

Individuals with cblC deficiency often suffer from a wide range of clinical complications, including developmental, metabolic, hematologic, neurologic, ophthalmologic and dermatologic findings. [64] Although considered a disease of infancy or childhood, patients can present at any time from the neonatal period to adulthood and can even be intrauterine affected. The disease has been classified into early-onset (infantile) and late-onset (noninfantile) forms.[65] Patients with early-onset disease, defined by the onset of symptoms before the age of one year, in general have severe systemic involvement. Symptoms include feeding difficulties, hypotonia, failure to thrive, seizures, microcephaly and developmental delay. Acidosis was observed in some patients. Progressive CNS findings were prominent and included hydrocephalus and neuroimaging evidence of cortical atrophy. Other systems became progressively involved. Nystagmus, pigmentary retinopathy, and decreased visual acuity were common. Hematological findings included thrombocytopenia, macrocytic anemia, megaloblastic marrow and/or hypersegmented polymorphonuclear neutrophils, leukopenia and neutropenia, probably all related to cellular folate deficiency. Also renal complications occur, which are not induced by increased MMA but are rather due to microangiopathy, resulting in hemolytic-uremic syndrome.[64] Mild facial anomalies have also been described in cblC patients; features included a long face, high forehead, large, floppy, and low-set ears, and flat philtrum. The morphologic characteristics became more evident after three years of age.[66] 
The late-onset of the disease seems rarer than the early-onset form. In addition to mild or even no hematological abnormalities, the clinical course is characterized by behavioral and psychiatric disturbances and rapid mental deterioration with confusion and disorientation, dementia, delirium, and psychosis.[67] Although its occurrence is rare, late-onset combined methylmalonic aciduria and homocystinuria, cblC type, should be considered when making a differential diagnosis in patients who present with neurological symptoms that are not consistent with common neurological diseases, especially when cognition, the pyramidal tract and peripheral nerves are involved.[68] Taken together, patients can be easily misdiagnosed or even missed.

Rosenblatt et al. (1997) reviewed 50 cblC patients who could be classified into the two broad phenotypes: 44 patients had early-onset, and six patients had later-onset diseases. The 44 patients presented in the first year of life with feeding difficulties, hypotonia, developmental delay, seizures, pigmentary retinopathy, and anemia. The outcome is often poor, as approximately one-fourth of the patients died, and those who survived suffered in general from severe neurological impairment.[64]

\section{Diagnosis}

CblC should be suspected when both tHcy and MMA are markedly elevated. CblC is a disorder of intracellular cbl metabolism caused by homozygous or compound heterozygous mutations in the MMACHC gene on chromosome 1p34. This disorder results in the impaired delivery of intracellular cbl to its two metabolically active forms, Mecbl and Adocbl. The decreased activity of these two enzymes causes elevations of tHcy and MMA as well as low-normal or reduced Met.[63,64] The overflow of Hcy into the transsulfuration pathway causes increases of cystathionine. In addition to overt B12 deficiency, other genetic defects in cbl metabolism, such as deficiency of cblD, cblF and cblJ, also result in increased of tHcy and MMA. The differential diagnosis is mainly based on gene analyses but may also be performed with functional complementation studies in cultured fibroblasts.

Because biochemical abnormalities are present in neonates, the diagnosis of cblC could be made by newborn screening, enabling the initiation of treatment prior to the development of notable pathology.[69] Key investigations for the diagnosis include measurements of plasma tHcy, MMA and Met and urinary organic acids. In acylcarnitine profiling, cblC patients often show increased propionylcarnitine (C3). Newborn screening can detect affected infants through decreased Met and elevated $\mathrm{C} 3$ or $\mathrm{C} 3 / \mathrm{C} 0$ and $\mathrm{C} 3 / \mathrm{C} 2$ ratios measured by tandem mass spectrometry (MS/MS). MMA and/or tHcy by MS/MS can be applied in second-tier analyses[61,70], although in theory, these analyses could be used directly in newborn screening.

Some common mutations are found in the MMACHC gene: c.271dupA (p.Arg91Lysfs $\left.{ }^{\star} 14\right)$, c.331C $>$ T (p.Arg111Ter) and c.394C>T (p.Arg132Ter).[71, 72] The p.Arg91Lysfs ${ }^{\star} 14$ and
p.Arg111Ter mutations were associated with early-onset disease, while the p.Arg132Ter mutation is primarily associated with late-onset disease.[73,74] Wang et al. (2010) reported that the c.609 G>A (p.W203X) mutation, which results in a premature termination codon at amino acid residue 203 located in the C-terminal region of $M M A C H C$, was detected in 39 of 46 patients, or $85 \%$ of alleles, making this mutation the most frequent in Chinese cblC patients.[70] Recently, it was reported a cblC patient who was heterozygous for the c.271dupA (p.Arg91Lysfs ${ }^{\star} 14$ ), at the MMACHC gene, and the c.515-1G>T, in the PRDX1 gene. [75. Both variants were in trans. The PRDX1 gene is located at the same locus than $M M A C H C$, but transcribed in the opposite strand. The c.515-1G $>\mathrm{T}$ is considered an epimutation, since it leads to a hypermethylated sequence encompassing the promoter and first exon of MMACHC gene.

\section{Management}

The main goal in cblC treatment is to reduce plasma levels of MMA and tHcy and normalize levels of Met. Treatment typically consists of a combined approach that utilizes mega-dose vitamin B12 IM., preferably in the form of hydroxycobalamin (OHcbl). In a guideline for the diagnosis and management of remethylation disorders, Huemer et al. (2017) recommended a starting dose of $1 \mathrm{mg}$ of OHcbl daily and administered parenterally.[76] Oral betaine is provided to enhances the remethylation via an alternative pathway and oral folinic acid ameliorates folate trapping. $[67,71,77]$ Protein restriction to reduce MMA is contraindicated because it results in a great reduction of Met.[78]

In a retrospective analysis of 50 patients with cblC disease, Rosenblatt et al. (1997) described a shorter interval between the onset of symptoms and the diagnosis in patients who died, likely because these individuals were sicker and progressed more rapidly than those who survived. The overall mortality rate was $30 \%(13 / 44)$ in early-onset cblC, and the six patients with late-onset cblC survived with good neurological outcomes. Although treatment systemic symptoms improved, neurological and ocular impairments persisted. OHcbl was used in $80 \%$ of the patients, and patients treated with cyanocobalamin presented no biochemical improvement.[64]

In a review of published case reports and case series, WeisfeldAdams et al. (2015) reported that maculopathy and nystagmus with abnormal vision affect a majority of children with earlyonset cblC, and strabismus and optic atrophy present at relatively high frequency. The treatment fails to prevent ocular disease, even with prenatal treatment through OHcbl administered to the mother, despite apparently adequate plasma Met levels and moderately elevated plasma tHcy. This study suggested a correlation between the severity of the ocular phenotype and the biochemical phenotype.[79]

Andersson, Marble and Shapira (1999) described the clinical and biochemical features of eight cblC patients who were treated for an average of 5.7 years. The age at diagnosis was between 1 week and 11 months, and treatment consisted of OHcbl IM. 
and daily oral carnitine supplementation. The earliest treated patient had one of the most severe developmental delay, showing that early treatment is no guarantee for better outcome. All patients presented with poor growth, feeding problems and/ or seizures.[80

More recently, in a retrospective study, Fischer et al. (2014) described 76 cblC patients with early-onset and 12 patients with late-onset diseases. The number of males affected was almost twice as high as the number of affected females. In early-onset group, 43 of the 76 patients presented symptoms in the first month of life. Parenteral OHcbl was prescribed to approximately $90 \%$ of the patients, but even after treatment, neurological and ophthalmological problems remained, such as developmental delay, seizures, failure to thrive, microcephaly and optic atrophy. Ten patients (11.4\%) died, and these individuals were primarily non-treated with OHcbl.[71]

\section{Severe 5, 10-Methylenetetrahydrofolate Reductase (Mthfr) Deficiency}

\section{Clinical Picture}

Severe methylenetetrahydrofolate reductase (MTHFR) deficiency is inherited as an autosomal recessive metabolic disorder of folate metabolism caused by mutations in the MTHFR gene on chromosome 1p36.3.[81] Homozygous or compound heterozygous loss-of-function mutations in MTHFR result in systemic 5MTHF deficiency and so hampered Hcy remethylation (Figure 1). This rare disorder is associated with slow brain growth, severe neurological disability, and untimely death.[82]

Homocystinuria due to MTHFR deficiency (OMIM ID: 236250) was first described in 1972 by Mudd et al.[11,83] in a 16-year-old boy with muscle weakness, seizures and abnormal encephalographic signs, a 17-year-old girl with mental degradation and schizophrenia and her sister. These three patients had homocystinuria but normal levels of Met, normal CBS activity in fibroblasts and low MTHFR activity. Severe MTHFR deficiency is biochemically characterized by hyperhomocysteinemia, homocystinuria, increased cystathionine, and low or low-normal Met, in contrast with CBS deficiency, which presents with elevated Met. In cultured fibroblasts, residual activity is less than $20 \%$ of the mean control value $[76,82,84]$ (Table 2 ).

A classical presentation suggestive of MTHFR deficiency is a neonate with acute neurological distress, including generalized muscular hypotonia, feeding problems, failure to thrive, lethargy, apnea, and eventually microcephaly.[7, 85] Patients may also present with late-onset disease during childhood and even in adulthood. The latter patients have a more variable picture, encompassing delayed developmental milestones, cognitive impairment and/or gait abnormalities, as well as mental degradation and progressive encephalopathy, compatible with myelopathy or ataxia, spasticity behavioral problems, an unspecific spectrum of psychiatric symptoms, and occasionally thrombosis. Megaloblastic and/or macrocytic anemia is typically absent. [7, 85, 86]

In contrast to the defects blocking MTR function, the block in the conversion of methylene-THF to methyl-THF does not result in the trapping of folates, as methyl-THF and does not interfere with the availability of reduced folates for purine and pyrimidine synthesis. This finding explains why patients do not have megaloblastic anemia and do not suffer from microangiopathy. [7] As the product of MTHFR methyl-THF is the circulating form of folate, MTHFR deficiency results in reduced folate levels, especially in the brain. Cerebral folate deficiency is a common finding in this inborn disorder.[87] Another interesting finding in the brain of patients with remethylation defects, compared to controls, is that choline, a precursor of betaine and so a source of methyl groups, seems deficient. The choline decreased levels is possibly a side effect of methyl groups depletion that should be produced by the transmethylation pathway.[88]

Age of presentation and clinical pattern correlate with residual enzyme activity.[7] In a review of 33 patients, Huemer et al. (2016) showed the median age at onset of symptoms was 1.25 months (mean 21 ; range 0.1 to 216 months). In 14 patients, the first symptoms were observed within the first month of life; and in another 11 patients, the symptoms were observed by the 6th month of life. The remaining five patients became symptomatic at the ages of 2, 5, 11, 13 and 18 years.[89]

In summary, MTHFR deficiency is a severe disease primarily affecting the CNS, likely due to the reduced availability of methylTHF and Met, causing reduced cerebral methylation as suggested by decreased SAM levels in CSF.[90,91] MRI imaging of the brain often reveals white matter disease and brain atrophy.[89]

\section{Diagnosis}

Froese et al. (2016) reported more than 100 different mutations in over 170 patients with severe MTHFR deficiency. Most mutations in the MTHFR gene are restricted to one or two families.[92] The c.665C $>\mathrm{T}$ (p.Ala222Val) is a polymorphism leading to a thermolabile MTHFR variant with a propensity for monomer dissociation and flavin adenine dinucleotide binding loss, showing a $70 \%$ and $35 \%$ reduction of enzyme activity in lymphocytes in homozygotes and heterozygotes, respectively, when compared with wild-type controls.[93] Notably, this SNP does not cause severe MTHFR deficiency. However, this common variant is a fascinating gene-environment example because in homozygotes with low-normal folate levels, this variant hampers Hcy and folate homeostasis, causing moderate hyperhomocysteinemia. This variant has been associated with many common diseases, such as cardiovascular disease and neurodegenerative disorders, but so far only confirmed as a risk factor in neural tube defects. $[84,94]$

Neonatal screening for MTHFR deficiency is feasible by detecting a decreased Met and Met-to-phenylalanine ratio in dried blood spots, followed by analysis of tHcy. To what extent 
are patients detected or missed remains obscure.[49] Direct measurement of MTHFR-specific activity can be performed in the liver tissue, leukocytes, lymphocytes and cultured fibroblasts. There is a rough inverse correlation between the specific activity of the reductase in cultured fibroblasts and clinical severity.[95]

\section{Management}

Untreated patients show progressive developmental delay and mental retardation, whereas some patients may also present with epilepsy and neurological disease (abnormal gait, spasticity).[7] The goal of treatment is to reduce plasma tHcy, normalize the levels of Met and folate, especially in CSF, and so presumably alleviate clinical symptoms. Treatment involves the administration (suggestive doses) of betaine (100-250 mg/kg/day in children and 5-20 g/day in adults) to provide an alternative pathway for Hcy remethylation. In addition, $\mathrm{OHcbl}(1-2 \mathrm{~g} / \mathrm{d})$ and folinic acid (400 mg/d) are prescribed. Pyridoxine, as a cofactor for CBS, may be administered to maximize the transsulfuration pathway and riboflavin as cofactor of the MTHFR enzyme. Met may be supplemented if its level remains low, despite treatment; in general, treatment improves the disease course in early-onset cases.[7, 82, 96, 97] Some studies have shown that treatment with folinic acid, Met, pyridoxine, and different cbl preparations but without betaine has generally been considered unsuccessful 7. In a systematic review, including 36 patients, the positive impact of early betaine treatment on the outcome in early-onset patients was shown: all five early treated patients survived with normal psychomotor development, while nine of ten non-treated and two of 21 late-treated patients died. In families with one or more deceased siblings, none of the treated but all of the untreated children died. Psychomotor development was impaired in all children with delayed treatment onset, despite the stabilization observed from the introduction of betaine treatment.[85]

Regarding the infantile forms, the only patients who have done well are those who were treated from birth. Early treatment with betaine following prenatal diagnosis has resulted in the best outcome.[98] Without treatment, these early-onset forms may rapidly progress to coma and potentially death by central respiratory failure. Since MTHFR deficiency is a potentially treatable disease, early diagnosis is crucial and treatment, in particularly betaine should be administered as early as possible.[92] Although single reports have described a benefit of treatment with folinic acid[99] or Met supplementation[96], the mainstay of treatment is betaine.[91]

\section{Conclusions}

Homocystinurias are a group of inborn errors of sulfur amino acid metabolism. Their joint manifestation is the accumulation of tHcy, however, the other sulfur amino acids show various and even invers profiles. CBS deficiency shows high Met with low cystathionine and cysteine. Whereas in the remethylation defects, Met is low-normal or decreased and cystathionine increased. Total cysteine in plasma is reduced in all homocystinurias because the elevated tHcy displaces cysteine from albumin, which binds the major fraction of tHcy and cysteine in plasma. At diagnosis, folate is typically low or (functionally) deficient in all homocystinurias. MTHFR deficiency blocks the production of methyl-THF, which is the circulation form of folate. In CBS deficiency, folate is often deficient at diagnosis probably due to the inhibition of MTHFR by the increased concentration of SAM. In cblC deficiency, a different mechanism kicks in: a dysfunctional MTR results in the accumulation of all folates as methyl-THF, which cannot be converted back to methylene-THF because MTHFR is physiologically none-reversible. These result in a functional folate deficiency despite that plasma folate may be normal or even increased because of the leakage of methylTHF out of the cell. Intracellularly, folate is not available for the folate-dependent pathways. In particular, the synthesis of thymidylate and purine will be compromised, which will hamper essential cellular functions, especially in cells that rapidly divide, such as those in bone marrow. This functional folate deficiency occurs in any cell, which may explain why so many different organ systems can be affected in cblC patients, particularly when compared to the other remethylation defect of MTHFR deficiency, which mainly affects the CNS.

Some clinical findings were found in all homocystinurias, including vascular disease, developmental delay and seizures. However, the complications of CNS differ in a wide variety of presentations and severities and are apparently less pronounced in CBS. Moreover, patients with remethylation defects typically do not present ectopia lentis and bone disturbances, tall stature and osteoporosis. Whereas hematological alterations, such as megaloblastic anemia, thrombocytopenia neutropenia and life-threatening microangiopathy, are specific findings of cblC deficiency.

Treatment that lowers plasma tHcy in CBS deficient results in improved clinical outcome[13], by reducing the incidence of vascular events $[19,20]$ or preventing mental retardation[57] and bone anomalies. [58] Remarkably, on treatment, the levels of plasma Hcy in general remained clearly elevated.[19, 100] Treated cblC patients have in general a marked reduction of tHcy, but neurological and ophthalmological problems usually remained.[71] 


\section{Abbreviations}

Hcy: Homocysteine; CBS: Cystathionine beta-synthase; MTHFR: Methylenetetrahydrofolate reductase; tHcy: Total homocysteine; Met: Methionine; ATP: Adenosine triphosphate; SAM: S-adenosylmethionine; SAH: S-adenosylhomocysteine; SAHH: S-adenosyl-L-homocysteine hydrolase; MTR: Methionine synthase; 5MTHF: 5-methyltetrahydrofolate; CSF: cerebrospinal fluid; BHMT: Betaine-homocysteine methyltransferase; Mecbl: Methylcobalamin; Adocbl: Adenosylcobalamin; HCU: Classical homocystinuria; MMA: Methylmalonic acid; CNS: Central nervous; IQ: Intelligence quotient; DNA: Deoxyribonucleic acid; DBS: Dried blood spot; MUT: Methylmalonyl CoA mutase; Cbl: Cobalamin; C3: Propionylcarnitine; C0: Free carnitine; C2: Acetylcarnitine; MS/ MS: Tandem mass spectrometry; IM: Intramuscular; OHcbl: Hydroxycobalamin; SNP: Single nucleotide polymorphisms; AR: Autosomal recessive; XLR: X-linked recessive; $\mathbf{C} \gamma \mathbf{L}$ : Cystathionine $\gamma$-lyase; THF: Tetrahydrofolate; SHMT: Serinehydroxymethyltransferase; MMAA: Methylmalonic aciduria type A; MMAB: Methylmalonic Aciduria cblB Type; MMADHC: methylmalonic aciduria and homocystinuria type D; MMACHC: methylmalonic aciduria and homocystinuria type $\mathrm{C}$ protein; LMBRD1: gene that encodes a lysosomal membrane protein that may be involved in the transport and metabolism of cobalamin affected in cblF; $\boldsymbol{A B C D 4}$ : gene ATP binding cassette subfamily D member 4 related to cblJ; HCFC1: gene host cell factor $\mathrm{C1}$ related to cblX; TCN2: transcobalamin 2; MTRR: gene methionine synthase reductase related to cblE.

\section{Acknowledgment}

National Coordination for Improvement of Higher Education Personnel (CAPES-Brazil) and the National Counsel of Technological and Scientific Development (CNPq-Brazil).

\section{Declaration of Conflict of Interests}

The authors declare that they have no conflict of interests.

\section{References}

1. Gellekink H, den Heijer M, Heil SG, Blom HJ. Genetic determinants of plasma total homocysteine. Semin Vasc Med. 2005;5(2):98-109. doi:10.1055/s-2005-872396

2. Booth GL, Wang EE. Preventive health care, 2000 update: screening and management of hyperhomocysteinemia for the prevention of coronary artery disease events. The Canadian Task Force on Preventive Health Care. CMAJ. 2000;163(1):21-29. https://www.cmaj.ca/content/163/1/21

3. Perła-Kaján J, Twardowski T, Jakubowski H. Mechanisms of homocysteine toxicity in humans. Amino Acids. 2007;32(4):561-572. doi:10.1007/s00726-006-0432-9
4. Hannibal L, Blom HJ. Homocysteine and disease: causal associations or epiphenomenons? Mol Aspects Med. 2017;53:36-42. doi:10.1016/j.mam.2016.11.003

5. Blom HJ, Smulders Y. Overview of homocysteine and folate metabolism. With special references to cardiovascular disease and neural tube defects. J Inherit Metab Dis. 2011;34(1):75-81. doi:10.1007/s10545-010-9177-4

6. Castro R, Rivera I, Blom HJ, Jakobs C, de Almeida IT. Homocysteine metabolism, hyperhomocysteinaemia and vascular disease: an overview. J Inherit Metab Dis. 2006;29(1):3-20. doi:10.1007/s10545-006-0106-5

7. Thomas M, Rosenblatt D. Severe methylenetetrahydrofolate deficiency. In: Ueland P, Rozen R, eds. MTHFR polymorphisms and disease. Georgetown, US: Landes Bioscience; 2005: 41-53

8. Burda P, Schäfer A, Suormala T, et al. Insights into severe 5,10-methylenetetrahydrofolate reductase deficiency: molecular genetic and enzymatic characterization of 76 patients. Hum Mutat. 2015;36(6):611-621. doi:10.1002/ humu.22779

9. Schiff M, Blom HJ. Treatment of inherited homocystinurias. Neuropediatrics. 2012;43(6):295304. doi:10.1055/s-0032-1329883

10. Lu YH, Huang YH, Cheng LM, et al. Homocystinuria in Taiwan: an inordinately high prevalence in an Austronesian aboriginal tribe, Tao. Mol Genet Metab. 2012;105(4):590595. doi:10.1016/j.ymgme.2012.01.021

11. Mudd SH, Levy HL, Kraus JP. Disorders of transulfuration. In: Valle D, ed. The Metabolic and Molecular Bases of Inherited Disease. 8th ed. New York, US: McGraw Hill; 2001: 2007-2056.

12. Moorthie S, Cameron L, Sagoo GS, Bonham JR, Burton H. Systematic review and meta-analysis to estimate the birth prevalence of five inherited metabolic diseases.J Inherit Metab Dis. 2014;37(6):889-898. doi:10.1007/s10545-0149729-0

13. Morris AA, Kožich V, Santra S, et al. Guidelines for the diagnosis and management of cystathionine betasynthase deficiency. J Inherit Metab Dis. 2017;40(1):4974. doi:10.1007/s10545-016-9979-0

14. Mudd SH, Skovby F, Levy HL, et al. The natural history of homocystinuria due to cystathionine beta-synthase deficiency. Am J Hum Genet. 1985;37(1):1-31. https://www. ncbi.nlm.nih.gov/pmc/articles/PMC1684548/

15. Taylor RH, Burke J, O'Keefe M, Beighi B, Naughton E. Ophthalmic abnormalities in homocystinuria: the value of screening. Eye (Lond). 1998;12(Pt 3a):427-430. doi:10.1038/ eye. 1998.100

16. Burke JP, O’Keefe M, Bowell R, Naughten ER. Ocular complications in homocystinuria-early and late treated. $\mathrm{Br}$ JOphthalmol. 1989;73(6):427-431. doi:10.1136/bjo.73.6.427 
17. Rajappa M, Goyal A, Kaur J. Inherited metabolic disorders involving the eye: a clinico-biochemical perspective. Eye (Lond). 2010;24(4):507-518. doi:10.1038/eye.2009.229

18. Magner M, Krupková L, Honzík T, Zeman J, Hyánek J, Kožich V. Vascular presentation of cystathionine betasynthase deficiency in adulthood. J Inherit Metab Dis. 2011;34(1):33-37. doi:10.1007/s10545-010-9146-y

19. Yap S, Naughten ER, Wilcken B, Wilcken DL, Boers GHJ. Vascular complications of severe hyperhomocysteinemia in patients with homocystinuria due to cystathionine beta-synthase deficiency: effects of homocysteinelowering therapy. Semin Thromb Hemost. 2000;26(3):335340. doi:10.1055/s-2000-8100

20. Yap S, Boers GH, Wilcken B, et al. Vascular outcome in patients with homocystinuria due to cystathionine betasynthase deficiency treated chronically: a multicenter observational study. Arterioscler Thromb Vasc Biol. 2001;21(12):2080-2085. doi:10.1161/hq1201.100225

21. Yap S. Classical homocystinuria: vascular risk and its prevention. J Inherit Metab Dis. 2003;26(2-3):259265. doi:10.1023/A:1024497419821

22. Andria G, Fowler B, Sebastio G. Disorders of Sulfur Amino Acid Metabolism. In: Saudubray JM, Berghe Gvd, Walter JH, ed., Inborn Metabolic Diseases - Diagnosis and Treatment. 4th ed. Berlin: Springer; 2006: 83-96.

23. Kluijtmans LA, Boers GH, Verbruggen B, Trijbels FJM, Nováková IRO, Blom HJ. Homozygous cystathionine beta-synthase deficiency, combined with factor $\mathrm{V}$ Leiden or thermolabile methylenetetrahydrofolate reductase in the risk of venous thrombosis. Blood. 1998;91(6):20152018. doi:10.1182/blood.V91.6.2015

24. Mandel H, Brenner B, Berant $\mathrm{M}$, et al. Coexistence of hereditary homocystinuria and factor V Leideneffect on thrombosis. N Engl J Med. 1996;334(12):763768. doi:10.1056/NEJM199603213341204

25. Skovby F, Gaustadnes M, Mudd SH. A revisit to the natural history of homocystinuria due to cystathionine beta-synthase deficiency. Mol Genet Metab. 2010;99(1):13. doi:10.1016/j.ymgme.2009.09.009

26. Al-Dewik N, Ali A, Mahmoud Y, et al. Natural history, with clinical, biochemical, and molecular characterization of classical homocystinuria in the Qatari population. J Inherit Metab Dis. 2019;42(5):818-830. doi:10.1002/jimd.12099

27. Abbott MH, Folstein SE, Abbey H, Pyeritz RE, Opitz JM. Psychiatric manifestations of homocystinuria due to cystathionine beta-synthase deficiency: prevalence, natural history, and relationship to neurologic impairment and vitamin B6-responsiveness. Am J Med Genet. 1987;26(4):959-969. doi:10.1002/ajmg.1320260427

28. Kaeser AC, Rodnight R, Ellis BA. Psychiatric and biochemical aspects of a case of homocystinuria. J Neurol
Neurosurg Psychiatry. 1969;32(2):88-93. doi:10.1136/ jnnp.32.2.88

29. Bracken P, Coll P. Homocystinuria and schizophrenia. Literature review and case report. J Nerv Ment Dis. 1985;173(1):51-55. doi:10.1097/00005053-19850100000008

30. De Franchis R, Sperandeo MP, Sebastio G, Andria G. Clinical aspects of cystathionine beta-synthase deficiency: how wide is the spectrum? The Italian Collaborative Study Group on Homocystinuria. Eur J Pediatr. 1998;157(S2):S67-S70. doi:10.1007/PL00014309

31. Ryan MM, Sidhu RK, Alexander J, Megerian JT. Homocystinuria presenting as psychosis in an adolescent. J Child Neurol. 2002;17(11):859860. doi:10.1177/08830738020170111707

32. Li SC, Stewart PM. Homocystinuria and psychiatric disorder: a case report. Pathology. 1999;31(3):221224. doi:10.1080/003130299105025

33. Weber DR, Coughlin C, Brodsky JL, et al. Low bone mineral density is a common finding in patients with homocystinuria. Mol Genet Metab. 2016;117(3):351354. doi:10.1016/j.ymgme.2015.12.003

34. Brenton DP, Dow CJ, James JI, Hay RL, Wynne-Davies R. Homocystinuria and Marfan's syndrome. A comparison. $J$ Bone Joint Surg Br. 1972;54(2):277-298. doi:10.1302/0301620X.54B2.277

35. Reish O, Townsend D, Berry SA, et al. Tyrosinase inhibition due to interaction of homocyst(e)ine with copper: the mechanism for reversible hypopigmentation in homocystinuria due to cystathionine beta-synthase deficiency. Am J Hum Genet. 1995;57(1):127-132.

36. Makins RJ, Gertner DJ, Lee PJ. Acute pancreatitis in homocystinuria. J Inherit Metab Dis. 2000;23(2):190191. doi:10.1023/A:1005682219894

37. Ilan Y, Eid A, Rivkind AI, Weiss D, Dubin $\mathrm{Z}$, Yatziv S. Gastrointestinal involvement in homocystinuria. J Gastroenterol Hepatol. 1993;8(1):6062. doi:10.1111/j.1440-1746.1993.tb01176.x

38. Sacharow SJ, Picker J, Levy H. Homocystinuria Caused by Cystathionine Beta-Synthase Deficiency. In: Pagon R, Adam M, Ardinger H, et al, eds. Gene Reviews. Seattle, US: Seattle University of Washington; 1993-2016. https:// www.ncbi.nlm.nih.gov/books/nbk1524/

39. Wilcken B. Disorders of Sulfur Amino Acids. In: Blau N, Hoffmann GF, Leonard JV, Clarke JTR, ed., Physician's Guide to the Treatment and Follow-Up of Metabolic Diseases. Berlin, GM: Springer; 2006: 105-115.

40. Kraus JP, Oliveriusová J, Sokolová J, et al. The human cystathionine beta-synthase (CBS) gene: complete sequence, alternative splicing, and polymorphisms. Genomics. 1998;52(3):312-324. doi:10.1006/geno.1998.5437 
41. Stenson PD, Mort M, Ball EV, et al. The Human Gene Mutation Database: towards a comprehensive repository of inherited mutation data for medical research, genetic diagnosis and next-generation sequencing studies. Hum Genet. 2017;136(6):665-677. doi:10.1007/s00439-0171779-6

42. Fowler B, Børresen AL, Boman N. Prenatal diagnosis of homocystinuria. Lancet. 1982;2(8303):875. doi:10.1016/ s0140-6736(82)90835-2

43. Poloni S, Sperb-Ludwig F, Borsatto T, et al. CBS mutations are good predictors for B6-responsiveness: A study based on the analysis of 35 Brazilian Classical Homocystinuria patients. Mol Genet Genomic Med. 2018;6(2):160170. doi:10.1002/mgg3.342

44. Yap S, Naughten E. Homocystinuria due to cystathionine beta-synthase deficiency in Ireland: 25 years' experience of a newborn screened and treated population with reference to clinical outcome and biochemical control. J Inherit Metab Dis. 1998;21(7):738-747. doi:10.1023/a:1005445132327

45. Zschocke J, Kebbewar M, Gan-Schreier H, et al. Molecular neonatal screening for homocystinuria in the Qatari population. Hum Mutat. 2009;30(6):10211022. doi:10.1002/humu.20994

46. Peterschmitt MJ, Simmons JR, Levy HL. Reduction of false negative results in screening of newborns for homocystinuria. N Engl J Med. 1999;341(21):15721576. doi:10.1056/nejm199911183412103

47. Bowron A, Barton A, Scott J, et al. Blood spot homocysteine: a feasibility and stability study. Clin Chem. 2005;51(1):257258. doi:10.1373/clinchem.2004.041640

48. McHugh D, Cameron CA, Abdenur JE, et al. Clinical validation of cutoff target ranges in newborn screening of metabolic disorders by tandem mass spectrometry: a worldwide collaborative project. Genet Med.2011;13(3):230254. doi:10.1097/gim.0b013e31820d5e67

49. Huemer M, Kožich V, Rinaldo P, et al. Newborn screening for homocystinurias and methylation disorders: systematic review and proposed guidelines. J Inherit Metab Dis. 2015;38(6):1007-1019. doi:10.1007/s10545-015-9830-Z

50. Huemer M, Mulder-Bleile R, Burda P, et al. Clinical pattern, mutations and in vitro residual activity in 33 patients with severe 5, 10 methylenetetrahydrofolate reductase (MTHFR) deficiency. J Inherit Metab Dis. 2016;39(1):115124. doi:10.1007/s10545-015-9860-6

51. Gan-Schreier H, Kebbewar M, Fang-Hoffmann J, et al. Newborn population screening for classic homocystinuria by determination of total homocysteine from Guthrie cards. J Pediatr. 2010;156(3):427-432. doi:10.1016/j. jpeds.2009.09.054

52. Refsum H, Fredriksen A, Meyer K, et al. Birth prevalence of homocystinuria. J Pediatr. 2004;144(6):830-832. doi:10.1016/j.jpeds.2004.03.004
53. Mudd SH, Edwards WA, Loeb PM, Brown MS, Laster L. Homocystinuria due to cystathionine synthase deficiency: the effect of pyridoxine. J Clin Invest. 1970;49(9):17621773. doi:10.1172/JCI106394

54. Walter JH, Wraith JE, White FJ, Bridge C, Till J. Strategies for the treatment of cystathionine beta-synthase deficiency: the experience of the Willink Biochemical Genetics Unit over the past 30 years. Eur J Pediatr. 1998;157(S2)(suppl 2):S71-S76. doi:10.1007/PL00014308

55. Wilcken B, Turner B. Homocystinuria. Reduced folate levels during pyridoxine treatment. Arch Dis Child. 1973;48(1):5862. doi:10.1136/adc.48.1.58

56. Thomas JA. Homocystinuria: diagnosis and Management. In: Bernstein LE, Rohr F, Helm JR, eds. Nutrition Management of Inherited Metabolic Diseases: Lessons from Metabolic University. Basel, SZ: Springer International; 2015:149-158.

57. Yap S, Rushe H, Howard PM, Naughten ER. The intellectual abilities of early-treated individuals with pyridoxinenonresponsive homocystinuria due to cystathionine betasynthase deficiency. J Inherit Metab Dis. 2001;24(4):437447. doi:10.1023/A:1010525528842

58. Lim JS, Lee DH. Changes in bone mineral density and body composition of children with well-controlled homocystinuria caused by CBS deficiency. Osteoporos Int. 2013;24(9):2535-2538. doi:10.1007/s00198-013-2351-4

59. Lerner-Ellis JP, Anastasio N, Liu J, et al. Spectrum of mutations in MMACHC, allelic expression, and evidence for genotype-phenotype correlations. Hum Mutat. 2009;30(7):1072-1081. doi:10.1002/humu.21001

60. Carrillo-Carrasco N, Venditti CP. Combined methylmalonic acidemia and homocystinuria, cblC type. II. Complications, pathophysiology, and outcomes. I Inherit Metab Dis. 2012;35(1):103-114. doi:10.1007/s10545-011-9365-X

61. Weisfeld-Adams JD, Morrissey MA, Kirmse BM, et al. Newborn screening and early biochemical follow-up in combined methylmalonic aciduria and homocystinuria, cblC type, and utility of methionine as a secondary screening analyte. Mol Genet Metab. 2010;99(2):116123. doi:10.1016/j.ymgme.2009.09.008

62. Han B, Cao Z, Tian L, et al. Clinical presentation, gene analysis and outcomes in young patients with early-treated combined methylmalonic acidemia and homocysteinemia (cblC type) in Shandong province, China. Brain Dev. 2015;38(5):491-497. doi:10.1016/j.braindev.2015.10.016

63. Mudd SH, Levy HL, Abeles RH. A derangement in B 12 metabolism leading to homocystinemia, cystathioninemia and methylmalonic aciduria. Biochem Biophys Res Commun. 1969;35(1):121-126. doi:10.1016/0006-291X(69)90491-4

64. Rosenblatt DS, Aspler AL, Shevell MI, Pletcher BA, Fenton WA, Seashore MR. Clinical heterogeneity and 
prognosis in combined methylmalonic aciduria and homocystinuria (cblC). J Inherit Metab Dis. 1997;20(4):528538. doi:10.1023/A:1005353530303

65. Thauvin-Robinet C, Roze E, Couvreur G, et al. The adolescent and adult form of cobalamin $\mathrm{C}$ disease: clinical and molecular spectrum. J Neurol Neurosurg Psychiatry. 2008;79(6):725-728. doi:10.1136/jnnp.2007.133025

66. Cerone R, Schiaffino MC, Caruso U, Lupino S, Gatti R. Minor facial anomalies in combined methylmalonic aciduria and homocystinuria due to a defect in cobalamin metabolism. J Inherit Metab Dis. 1999;22(3):247250. doi:10.1023/A:1005521702298

67. Martinelli D, Deodato F, Dionisi-Vici C. Cobalamin C defect: natural history, pathophysiology, and treatment. J Inherit Metab Dis. 2011;34(1):127-135. doi:10.1007/s10545010-9161-Z

68. Wang X, Sun W, Yang Y, Jia J, Li C. A clinical and gene analysis of late-onset combined methylmalonic aciduria and homocystinuria, cblC type, in China. J Neurol Sci. 2012;318(1-2):155-159. doi:10.1016/j.jns.2012.04.012

69. Fuchs LR, Robert M, Ingster-Moati I, et al. Ocular manifestations of cobalamin $\mathrm{C}$ type methylmalonic aciduria with homocystinuria. J AAPOS. 2012;16(4):370375. doi:10.1016/j.jaapos.2012.02.019

70. Wang F, Han L, Yang Y, et al. Clinical, biochemical, and molecular analysis of combined methylmalonic acidemia and hyperhomocysteinemia (cblC type) in China. J Inherit Metab Dis. 2010;33(S3)(suppl 3):S435-S442. doi:10.1007/ s10545-010-9217-0

71. Fischer S, Huemer M, Baumgartner M, et al. Clinical presentation and outcome in a series of 88 patients with the cblC defect. J Inherit Metab Dis. 2014;37(5):831840. doi:10.1007/s10545-014-9687-6

72. Nogueira C, Marcão A, Rocha H, et al. Molecular picture of cobalamin C/D defects before and after newborn screening era. J Med Screen. 2017;24(1):611. doi:10.1177/0969141316641149

73. Lerner-Ellis JP, Tirone JC, Pawelek PD, et al. Identification of the gene responsible for methylmalonic aciduria and homocystinuria, cblC type. Nat Genet. 2006;38(1):93100. doi:10.1038/ng1683

74. Huemer M, Scholl-Bürgi S, Hadaya K, et al. Three new cases of late-onset cblC defect and review of the literature illustrating when to consider inborn errors of metabolism beyond infancy. Orphanet J Rare Dis. 2014;9(1):161. doi:10.1186/s13023-014-0161-1

75. Guéant JL, Chéry C, Oussalah A, et al. APRDX1 mutant allele causes a MMACHC secondary epimutation in cblC patients. Nat Commun. 2018;9(1):67. doi:10.1038/s41467017-02306-5
76. Huemer M, Diodato D, Schwahn B, et al. Guidelines for diagnosis and management of the cobalamin-related remethylation disorders $\mathrm{cblC}$, cblD, cblE, cblF, cblG, cblJ and MTHFR deficiency. J Inherit Metab Dis. 2017;40(1):2148. doi:10.1007/s10545-016-9991-4

77. Pastore A, Martinelli D, Piemonte F, et al. Glutathione metabolism in cobalamin deficiency type C (cblC). J Inherit Metab Dis. 2014;37(1):125-129. doi:10.1007/s10545-0139605-3

78. Manoli I, Myles JG, Sloan JL, et al. A critical reappraisal of dietary practices in methylmalonic acidemia raises concerns about the safety of medical foods. Part 2: cobalamin C deficiency. Genet Med. 2016;18(4):396-404. doi:10.1038/ gim.2015.107

79. Weisfeld-Adams JD, McCourt EA, Diaz GA, Oliver SC. Ocular disease in the cobalamin $C$ defect: a review of the literature and a suggested framework for clinical surveillance. Mol Genet Metab. 2015;114(4):537546. doi:10.1016/j.ymgme.2015.01.012

80. Andersson HC, Marble M, Shapira E. Long-term outcome in treated combined methylmalonic acidemia and homocystinemia. Genet Med. 1999;1(4):146150. doi:10.1097/00125817-199905000-00006

81. Goyette P, Sumner JS, Milos R, et al. Human methylenetetrahydrofolate reductase: isolation of cDNA, mapping and mutation identification. Nat Genet. 1994;7(2):195-200. doi:10.1038/ng0694-195

82. Rosenblatt D, Erbe R. Inherited disorders of folate and cobalamin transport and metabolism. In: Valle $\mathrm{D}$, ed. The Metabolic and Molecular Bases of Inherited Disease. 8th ed. New York, US: McGraw-Hill; 2001:3897-3933.

83. Mudd SH, UhlendorfBW, Freeman JM, et al. Homocystinuria associated with decreased methylenetetrahydrofolate reductase activity. Biochem Biophys Res Commun. 1972;46(2):905-912. doi:10.1016/S0006-291X(72)80227-4

84. Watkins D, Rosenblatt DS. Update and new concepts in vitamin responsive disorders of folate transport and metabolism. J Inherit Metab Dis. 2012;35(4):665670. doi:10.1007/s10545-011-9418-1

85. Diekman EF, de Koning TJ, Verhoeven-Duif NM, Rovers MM, van Hasselt PM. Survival and psychomotor development with early betaine treatment in patients with severe methylenetetrahydrofolate reductase deficiency. JAMA Neurol. 2014;71(2):188-194. doi:10.1001/ jamaneurol.2013.4915

86. Saudubray JM, Berghe G, Walter JH. Inborn Metabolic Diseases: Diagnosis and Treatment. 5th ed. Berlin, GM: Springer; 2012.

87. Knowles L, Morris AA, Walter JH. Treatment with Mefolinate (5-Methyltetrahydrofolate), but Not Folic Acid or 
Folinic Acid, Leads to Measurable 5-Methyltetrahydrofolate in Cerebrospinal Fluid in Methylenetetrahydrofolate Reductase Deficiency. JIMD Rep. 2016;29:103107. doi:10.1007/8904_2016_529

88. Debray FG, Boulanger Y, Khiat A, et al. Reduced brain choline in homocystinuria due to remethylation defects. Neurology. 2008;71(1):44-49. doi:10.1212/01. wnl.0000316391.40236.c3

89. Huemer M, Mulder-Bleile R, Burda P, et al. Clinical pattern, mutations and in vitro residual activity in 33 patients with severe 5, 10 methylenetetrahydrofolate reductase (MTHFR) deficiency. J Inherit Metab Dis. 2016;39(1):115124. doi:10.1007/s10545-015-9860-6

90. Surtees R, Leonard J, Austin S. Association of demyelination with deficiency of cerebrospinal-fluid S-adenosylmethionine in inborn errors of methyl-transfer pathway. Lancet. 1991;338(8782-8783):1550-1554. doi:10.1016/01406736(91)92373-A

91. Strauss KA, Morton DH, Puffenberger EG, et al. Prevention of brain disease from severe 5,10-methylenetetrahydrofolate reductase deficiency. Mol Genet Metab. 2007;91(2):165175. doi:10.1016/j.ymgme.2007.02.012

92. Froese DS, Huemer M, Suormala T, et al. Mutation Update and Review of Severe Methylenetetrahydrofolate Reductase Deficiency. Hum Mutat. 2016;37(5):427-438. doi:10.1002/ humu. 22970

93. Forges T, Chery C, Audonnet S, Feillet F, Gueant J-L. Life-threatening methylenetetrahydrofolate reductase (MTHFR) deficiency with extremely early onset: characterization of two novel mutations in compound heterozygous patients. Mol Genet Metab. 2010;100(2):143148. doi:10.1016/j.ymgme.2010.03.002
94. Blom HJ, Shaw GM, den Heijer M, Finnell RH. Neural tube defects and folate: case far from closed. Nat Rev Neurosci. 2006;7(9):724-731. doi:10.1038/nrn1986

95. Rosenblatt DS, Lue-Shing H, Arzoumanian A, Low-Nang L, Matiaszuk N. Methylenetetrahydrofolate reductase (MR) deficiency: thermolability of residual MR activity, methionine synthase activity, and methylcobalamin levels in cultured fibroblasts. Biochem Med Metab Biol. 1992;47(3):221-225. doi:10.1016/0885-4505(92)90029-X

96. Abeling NG, van Gennip AH, Blom H, et al. Rapid diagnosis and methionine administration: basis for a favourable outcome in a patient with methylene tetrahydrofolate reductase deficiency. J Inherit Metab Dis. 1999;22(3):240242. doi:10.1023/A:1005509400481

97. Sibani S, Leclerc D, Weisberg IS, et al. Characterization of mutations in severe methylenetetrahydrofolate reductase deficiency reveals an FAD-responsive mutation. Hum Mutat. 2003;21(5):509-520. doi:10.1002/humu.10193

98. Watkins D, Rosenblatt D, S., Fowler B. Disorders of Cobalamin and Folate Transport and Metabolism. In: Saudubray JM, Berghe Gvd, Walter JH, ed., Inborn Metabolic Diseases: Diagnosis and treatment. 5th ed. Heidelberg, GM: Springer; 2012.

99. Crushell E, O’Leary D, Irvine AD, O’Shea A, Mayne PD, Reardon W. Methylenetetrahydrofolate reductase (MTHFR) deficiency presenting as a rash. Am J Med Genet A. 2012;158A(9):2254-2257. doi:10.1002/ajmg.a.35479

100. Wilcken DE, Wilcken B. The natural history of vascular disease in homocystinuria and the effects of treatment. J Inherit Metab Dis. 1997;20(2):295300. doi:10.1023/A:1005373209964 